\title{
Clinical presentation and laboratory findings for the first autochthonous cases of dengue fever in Madeira island, Portugal, October 2012
}

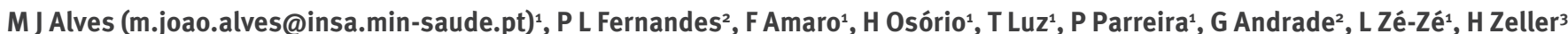

1. Centro de Estudos de Vectores e Doenças Infecciosas, Instituto Nacional de Saúde Dr. Ricardo Jorge, Águas de Moura, Portugal

2. Laboratório de Patologia Clínica, Hospital Dr. Nélio Mendonça, Funchal, Região Autónoma da Madeira, Portugal

3. European Centre for Disease Prevention and Control (ECDC), Stockholm, Sweden

Citation style for this article:

Alves MJ, Fernandes PL, Amaro F, Osório H, Luz T, Parreira P, Andrade G, Zé-Zé L, Zeller H. Clinical presentation and laboratory findings for the first autochthonous cases of dengue fever in Madeira island, Portugal, October 2012. Euro Surveill. 2013;18(6):pii=20398. Available online: http://www.eurosurveillance.org/ ViewArticle.aspx?Articleld $=20398$

An outbreak of dengue fever in Madeira island was reported in 2012. Clinical and laboratory findings of the first two laboratory-confirmed autochthonous cases are reported. Both cases had fever $\left(\geq 38{ }^{\circ} \mathrm{C}\right)$ and petechial rash. Symptoms also included myalgia, asthenia, nausea, vomiting, anorexia, diffuse abdominal pain, and diarrhoea. The two cases were confirmed by serology and one tested positive for a dengue viral sequence. Dengue virus serotype DEN-1 was identified with probable Central or South American origin.

Dengue virus (family Flaviviridae, genus Flavivirus) is the aetiological agent of dengue fever, a mosquitoborne infection endemic in the tropics and subtropics. The National Institute of Health Dr. Ricardo Jorge (INSA) performs reference laboratory diagnosis of dengue in Portugal. Human cases identified annually in this laboratory are imported from endemic areas. In terms of number of positive samples, these areas include by order of importance, mainly Brazil, but also TimorLeste, India, Cape Verde, Mexico, Thailand, Angola, Pakistan and Vietnam. In the beginning of October 2012, for the first time, two autochthonous cases of dengue fever from Madeira archipelago, Portugal were diagnosed. These signaled the beginning of an outbreak and the latest published data includes 2,144 reported autochthonous cases of dengue fever in Madeira island [1]. Clinical and laboratory findings of these first two cases are reported.

\section{Case reports}

\section{Case 1}

On 20 September, 2012 a 16 year-old woman developed febrile illness with temperature up to $38.5^{\circ} \mathrm{C}$, nausea, vomiting, anorexia, diffuse abdominal pain and diarrhoea. Five days later she presented at the local hospital, with prostration, and, in the second day after admission developed petechial rash at the upper and lower limbs that spread to the lower abdomen within 24 hours.
The patient, who lives in Caniço in the neighbourhood of the town of Funchal and studies in Funchal, mentioned traveling to Algarve, south of mainland Portugal, six weeks before and had not been vaccinated against flaviviruses such as yellow fever, tick-borne encephalitis and Japanese encephalitis viruses.

The first laboratory findings in the hospital showed thrombocytopenia with minimal platelet count $\left(65 \times 10^{9} / \mathrm{L}\right.$, norm: $\left.150-400 \times 10^{9} / \mathrm{L}\right)$, leucopenia $\left(2.4 \times 10^{9} / \mathrm{L}\right.$, norm: $\left.4.5-13.5 \times 10^{9} / \mathrm{L}\right)$ and elevated transaminases (alanine/glutamic pyruvic transaminase (ALT/GPT): $117 \mathrm{U} / \mathrm{L}$, norm: $17-63 \mathrm{U} / \mathrm{L}$; aspartate/ glutamic-oxaloacetic (AST/GOT): $95 \mathrm{U} / \mathrm{L}$, norm: 10-50 $\mathrm{U} / \mathrm{L}$ ). In the Funchal hospital the screening test for dengue was performed by immunochromatography (NADAL dengue fever IgG/IgM) followed by dengue IgM and IgG capture enzyme-linked immunosorbent assay (ELISA) (Panbio). The serum sample taken on day 6 after the onset of febrile illness was positive by immunochromatography, ELISA IgM positive (5.91) and IgG negative (0.07) (cut-off >1.1).

In the National Institute of Health, sera samples were tested by immunofluorescent assay in-house (IgG and IgM) and Euroimmun commercial test (IgM). The serum sample (day 11 post onset) was positive for dengue virus specific IgM with a titre of 256 (cut-off $=16$ ) and IgG with a titre of 1,024 (cut-off $=32$ ). The serum sample was also tested for immunoglobulins specific to other flaviviruses, such as yellow fever, tick-borne encephalitis, West Nile and Japanese encephalitis viruses by immunofluorescent assays and all assay results were negative. The patient recovered without complications and was discharged from the hospital on the eighth day of hospitalisation.

\section{Case 2}

On 27 September 2012, a 44 year-old man developed febrile illness with temperature up to $38.0^{\circ} \mathrm{C}$, myalgia 
and asthenia. Two days later he visited the local hospital and presented also with petechial rash at the upper and lower limbs.

The patient who lives and works in Santa Luzia, a local administrative unit of the city of Funchal, did not travel abroad and reported no vaccination against yellow fever, tick-borne encephalitis and Japanese encephalitis viruses.

The first laboratory findings in the hospital showed thrombocytopenia with minimal platelet count (74 $\times 10^{9} / \mathrm{L}, \quad$ norm: $\left.150-400 \times 10^{9} / \mathrm{L}\right), \quad$ leucopenia

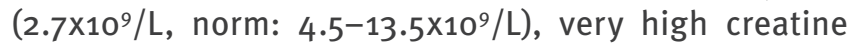
kinase (CK) $(1,146 \mathrm{ng} / \mathrm{ml}$, norm: $20-200 \mathrm{ng} / \mathrm{ml})$, and slightly elevated AST/GOT (58 U/L, norm: 10-50 U/L), high lactate dehydrogenase (LDH) (395 U/L, norm: $<246$ $\mathrm{U} / \mathrm{L}$ ). A sample collected on day 2 post onset was positive by immunochromatography, ELISA IgM positive (5.32), unusually at day 2 , and IgG negative (0.18). The IgM antibodies in cases of dengue infection are usually detected after the fifth day following the onset of symptoms suggesting that maybe, in this case, the date of the onset was not properly determined.

In the National Institute of Health the serum sample (day 4 post symptom onset) tested by immunofluorescent assay was positive for dengue virus specific IgM with a titre of 1,024 (cut-off $=16$ ) and IgG with a titre of 512 (cut-off =32). The serum sample was also subjected to immunofluorescent assays for immunoglobulins specific to other flaviviruses, such as yellow fever, tickborne encephalitis, West Nile and Japanese encephalitis viruses and all assay results were negative.

The patient recovered without complications and was discharged from the hospital on the fourth day of hospitalisation. Twelve days after the onset of symptoms he returned for further evaluation, and the blood count had returned to normal (leukocytes $\left(7.2 \times 10^{9} / \mathrm{L}\right.$,

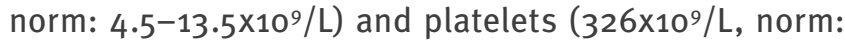
$\left.\left.150-400 \times 10^{9} / \mathrm{L}\right)\right)$.

\section{Molecular laboratory analysis}

In the National Institute of Health laboratory, nucleic acids were extracted from ethylenediaminetetraacetic acid (EDTA) blood samples using NucliSens easyMAG platform (bioMérieux). The presence of dengue virus RNA was checked by one-step conventional reverse transcription-polymerase chain reaction (RT-PCR) using generic flavivirus primers targeting the non-structural protein $5\left(\mathrm{NS}_{5}\right)$ gene $[2,3]$ followed by dengue specific assays including multiplex RT-PCR targeting the corepre-membrane $(\mathrm{CprM})$ region $[4,5]$ and real time RT-PCR [6].

Fragments obtained by nested-PCR (NS5, 163 bp and CprM region, 454 bp) were sequenced bi-directionaly. The 454 bp CprM partial polyprotein gene sequence was deposited on the GenBank database under accession number KC248375. Similarity searches were made within the GenBank data set using the basic local alignment search tool (BLAST) BLASTN algorithm [7].

For case 1, RT-PCR for flaviviruses was negative as well as the results from both dengue specific assays (conventional multiplex and real time RT-PCR) on day 11 post onset of disease. For case 2, RT-PCR for flaviviruses was positive as well as dengue specific real time RT-PCR and conventional multiplex RT-PCR on day 5 post onset.

Four distinct dengue virus serotypes (DEN-1, DEN2, DEN-3 and DEN-4) are recognised [8]. Sequence

\section{FIGURE}

Phylogenetic analysis of a viral sequence derived from an autochthonous case of dengue fever in Madeira, Portugal, October 2012

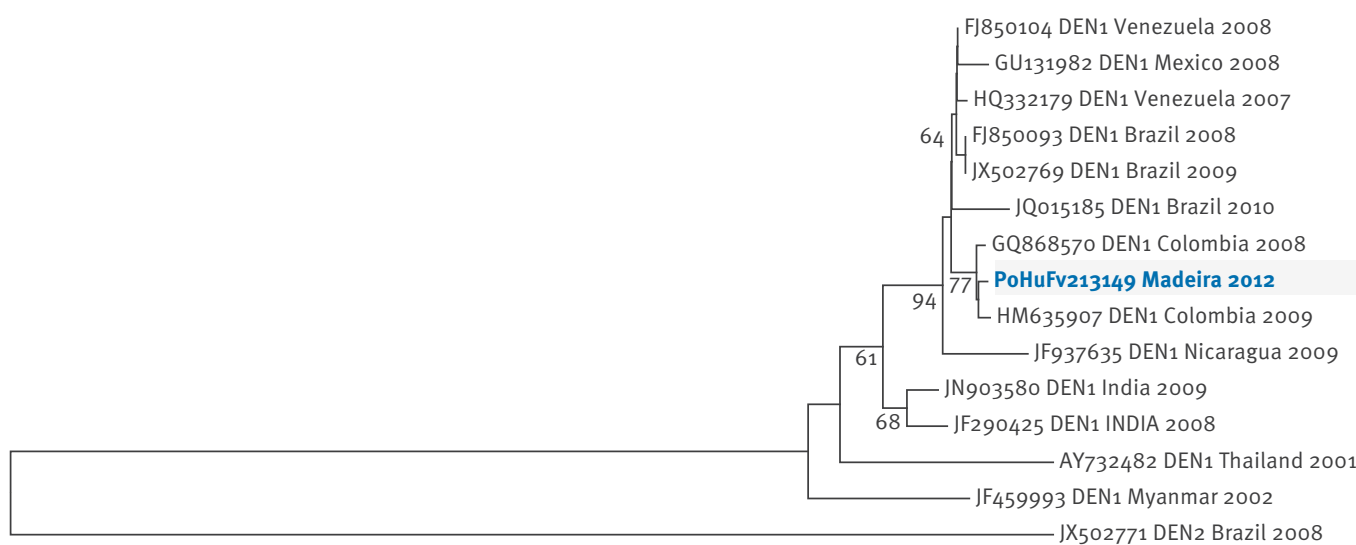


analysis of $\mathrm{NS}_{5}$ and $\mathrm{CprM}$ partial sequences derived from case 2 by BLASTN and a preliminary phylogenetic analysis based on CprM nucleotide sequences ascertain DEN serotype 1 identified as related to viruses circulating in latin America namely Colombia, Venezuela, and the Roraima region in northern Brazil [7] (Figure). The virus isolated in Madeira is also associated with DEN-1 strains recognised as belonging to genotype $\mathrm{V}$ (e.g. in the Figure, GenBank accession numbers: JX502769, JQ015185), a genotype that represents most of the strains collected in the Americas, West Africa and a limited number of strains collected from Asia [9].

For the case 2, the viral isolation in Vero E6 cells was achieved and the full genome sequence is in progress.

\section{Discussion and conclusions}

Infection with dengue virus causes a wide spectrum of human disease, from asymptomatic infections, to classic dengue fever and to haemorrhagic disease. More severe disease is usually associated with secondary infections with heterologous serotypes $[10,11]$. Between early October 2012 and the beginning of 2013, 2,144 autochthonous dengue virus infections were reported in the island of Madeira. There were no reports of severe disease and a decrease of new cases in the last weeks of 2012 was observed [1].

Dengue virus is transmitted by Aedes mosquitoes, namely Aedes (Ae.) aegypti and Ae. albopictus. Ae. aegypti was introduced in Madeira probably from a Caribbean country (personal communication, M Melim, 2009) and its presence was detected for the first time in 2005 , in the city of Funchal [12]. Although vector control measures to eradicate or to reduce the spread of this invasive mosquito species were taken, it became the most abundant mosquito species namely in the sites selected for the national vector surveillance programme in 2010 and 2011 [13].

The first cases of the dengue fever outbreak in Madeira, as the majority of all cases, happened in Funchal, the urban environment where the mosquito Ae. aegypti was first found [12]. In 2012, the combination of the high vector density with multiple breeding sites in the city [13] and lack of immunity of the population are likely to explain the dimension of the outbreak.

After the initial cases presented here and as of the end of November 2012, the National Institute of Health laboratory tested an additional 43 samples by RT-PCR, 28 of which were found positive. In all of these cases DEN-1 serotype was identified.

The circulation of the four serotypes of dengue in the Caribbean region and South America is described [8]. Hence as it has not yet been identified how the mosquito and the virus were introduced in Madeira, we can assume that there is a risk of new introductions, and spread of new virus serotypes in the next years. As it is well known, the absence of long-term cross-immunity among the different dengue serotypes allows for multiple sequential infections with heterologous serotypes and the occurrence of cases with more severe disease.

Vector control and surveillance in the territory to avoid the mosquitos' introduction to other regions of Madeira archipelago and to the mainland is necessary and has already been implemented by the local health authorities.

After 2012, the clinical cases should also be evaluated and serotyped due to the risk of new virus introductions.

In cases of dengue outbreaks, the laboratory has an essential role for early detection and reporting of the first cases. This contributes to the decision to implement vector control measures. Laboratory tests are important for precise identification of the aetiological agent and to retrace its origin. The reference laboratory also provides a quality control for other laboratories and helps with the continuous monitoring of suspected cases

\section{Conflict of interest}

None

Authors' contributions

All authors collaborated in the work and in the manuscript presented here. MJA: laboratory coordination at INSA and manuscript preparation; PLF, GA: clinical data and laboratory techniques in Madeira; MJA, FA, HO,LZZ: molecular diagnosis at INSA; MJA, TL, PP: serological diagnosis at INSA; LZZ, $\mathrm{HZ}$ : data analysis and suggestions to the manuscript.

\section{References}

1. European Centre for Disease Prevention and Control (ECDC). Monitoring current threats in week 3/2013: ECDC Communicable Disease Threats Report (CDTR). Stockholm: ECDC. [Accessed 07 Feb 2013]. Available from: http://www. ecdc.europa.eu/en/press/news/Lists/News/ECDC DispForm. aspx? List $=32$ e 43 ee $8 \% 2$ De230\%2D 4424\%2Da783\%2D 8574212 4029 a \& ID $=827 \&$ RootFolder $=\% 2$ Fen $\% 2$ Fpress $\% 2$ Fnews $\% 2$ FLis ts \%2FNews

2. Briese $T$, Jia XY, Huang C, Grady LJ, Lipkin WI. Identification of a Kunjin/West Nile-like flavivirus in brains of patients with New York encephalitis. Lancet. 1999;354(9186): 1261-2. http:// dx.doi.org/10.1016/S0140-6736(99)04576-6

3. Briese T, Rambaut A, Pathmajeyan M, Bishara J, Weinberger M, Pitlik S, et al. Phylogenetic Analysis of a Human Isolate from the 2000 Israel West Nile virus Epidemic. Emerg Infect Dis. 2002; 8(5): 528-31. http://dx.doi.org/10.3201/eido805.010324 PMid:11996693 PMCid:2732485

4. Lanciotti RS, Calisher CH, Gubler DJ, Chang GJ, Vorndam AV. Rapid detection and typing of dengue viruses from clinical samples by using reverse transcriptase-polymerase chain reaction. J Clin Microbiol. 1992;30(3): 545-51.

5. Saxena P, Dash PK, Santhosh SR S, Shrivastava A, Parida M, Rao PL. Development and Evaluation of one step single tube multiplex RT-PCR for rapid detection and typing of dengue viruses. Virol J. 2008;30(5):20. http://dx.doi.org/10.1186/1743422X-5-20

PMid:18234069 PMCid:2267776

6. Domingo C, Niedrig M, Teichmann A, Kaiser M, Rumer L, Jarman $R G$, et al. 2nd International external quality control assessment for the molecular diagnosis of dengue infections. PLoS Negl Trop Dis. 2010;4(10). 
7. Altschul SF, Madden TL, Schäffer AA, Zhang J, Zhang

Z, Miller W, et al. Gapped BLAST and PSI-BLAST: a new

generation of protein database search programs. Nucleic

Acids Res. 1997;25(17):3389-402. http://dx.doi.org/10.1093/

nar/25.17.3389

PMid:9254694 PMCid:146917

8. Guzman MG, Halstead SB, Artsob H, Buchy P, Farrar J, Gubler DJ, et al. Dengue: a continuing global threat. Nat Rev Microbiol. 2010;8(12 Suppl):S7-16.

9. Weaver SC, Vasilakis N. Molecular evolution of dengue viruses: contributions of phylogenetics to understanding the history and epidemiology of preeminent arboviral disease. Infect Genet Evol. 2009;9(4): 523-40. http://dx.doi.org/10.1016/j. meegid.2009.02.003

PMid:19460319

10. Horstick O, Farrar J, Lum L, Martinez E, San Martin JL,

Ehrenberg J, et al. Reviewing the development, evidence base, and application of the revised dengue case classification.

Pathog Glob Health. 2012;106(2):94-101. http://dx.doi.org/10.1 179/2047773212Y.0000000017

PMid:22943544 PMCid:3408880

11. Halstead SB. Immunological parameters of togavirus disease syndromes. In Schlesinger RW, ed. The togaviruses: biology, structure, replication. New York: Academic Press; 1980.p 107-70.

12. Margarita Y, Santos Grácio AJ, Lencastre I, Silva AC, Novo T, Sousa C, et al. Mosquitos de Portugal: primeiro registo de Aedes (Stegomia) aegypti Linnaeus, 1762 (Diptera, Culicidae) na Ilha da Madeira. [First record of Aedes (Stegomia) aegypti (Linnaeus, 1762) (Diptera, Culicidae) in Madeira Island Portugal]. Acta Parasitológica Portuguesa. 2006;13(1):59-61. Portuguese.

13. Alves MJ, Osório H, Zé-Zé L. Relatório REVIVE 2011 Culicídeos. Dezembro 2011.Lisbon: Instituto Nacional de Saúde Dr. Ricardo Jorge (INSA). 2011. Portuguese. 